\title{
PROSTORSKI ASPEKTI MANJŠINSKE PROBLEMATIKE V LUČI SLOVENSKEGA SOCIALNOGEOGRAFSKEGA IN POLITIČNOGEOGRAFSKEGA PROUČEVANJA
}

\author{
Milan Bufon* \\ Izvleček \\ UDK $911.3: 323.15=863$ \\ Prispevek obravnava izkušnje in uspehe slovenske socialne in politične geografije pri \\ obravnavi slovenskih narodnostnih skupnosti $v$ zamejstvu, ter italijanske in madžarske \\ narodnostne manjšine $v$ Sloveniji.
}

Ključne besede: Socialna geografija, politična geografija, narodnostne manjšine, Slovenija.

\section{SPATIAL ASPECTS OF THE MINORITY PROBLEMS IN THE LIGHT OF SLOVENIAN SOCIOGEOGRAPHICAL AND POLITICOGEOGRAPHICAL INVESTIGATIONS}

\section{Abstract}

The paper discusses the experiences and successes of Slovenian social and political geographies while investigating Slovenian national minorities outside the borders of Slovenia and the Italian and the Hungarian national minorities in Slovenia.

Key words: Social geography; Political geography; National minorities; Slovenia.

\footnotetext{
*Dr., doc., Znanstveno raziskovalno središče Repiblike Slovenije, Garibaldijeva 18, SI 6000 Koper, Slovenija
} 


\section{UVOD}

Prof. Vladimir Klemenčič je kot osnovno izhodišče socialnogeografskega proučevanja (Klemenčič, 1992a) opredelil sprotno odkrivanje regionalnih procesov in prostorskih struktur s težiščem na vrednotenju inovacij posameznih elementov prostorskih struktur. V spoznanju, da je tudi slovenski prostor v procesu stalnega spreminjanja in pod vplivom zakonitosti notranjega in zunanjega družbenoekonomskega in političnega razvoja, so se tako na njegovo pobudo od srede šestdesetih let dalje pričele v Sloveniji raziskave, ki so s socialnogeografsko metodologijo spremljale preobrazbo slovenskega podeželja $\mathrm{v}$ okviru procesov industrializacije, urbanizacije in deagrarizacije. Na tej osnovi se je razmahnilo tudi proučevanje socialno-ekoloških strukturnih problemov modernizacije in transformacije slovenskega naselitvenega prostora ter poglabljanje $\mathrm{v}$ politično in etničnogeografske probleme $\mathrm{v}$ sklopu obravnav skupnega slovenskega prostora in geopolitičnega položaja Slovenije. Ker je ravno proučevanje slovenskih manjšin $v$ sosednjih deželah in tudi $v$ Sloveniji živečih nacionalnih manjšin, največkrat $\mathrm{v}$ povezavi s problematiko meja in prekomejnih odnosov, bilo deležno večje mednarodne pozornosti in pripomoglo tako $\mathrm{k}$ mednarodnemu uveljavljanju posebne raziskovalne metodologije, ki so jo slovenski geografi razvili na osnovi socialnogeografskih teoretičnih in aplikativnih izhodišč, bo pričujoči prispevek $\mathrm{v}$ nadaljevanju podrobneje obravnaval ta tematski sklop in iz njega izhajajočo problematiko.

\section{METODOLOŠKA IZHODIŠČA : NA PREHODU MED SOCIALNOGEOGRAFSKIMI IN SODOBNIMI POLITIČNOGEOGRAFSKIMI KONCEPTI}

Po prevladujoči definiciji je socialnogeografska koncepcija naravnana na odkrivanje oblik prostorske organizacije, družbenih procesov in inovacij $\mathrm{v}$ prostoru. Vsi ti elementi se izražajo zlasti preko temeljnih oziroma geografsko relevantnih človekovih dejavnosti, kot so bivanje ali življenje v skupnosti, delo, izkoriščanje prostega časa, izobraževanje, oskrbovanje in s temi dejavnostmi povezane infrastrukturne in komunikacijske zahteve. Socialna geografija si tako zastavlja troje prvenstvenih nalog : določiti družbenoprostorske strukture oziroma razmestitev prostorsko aktivnih družbenih skupin, ugotoviti prostorski sistem, znotraj katerega se uveljavljajo prostorske funkcije in procesi posameznih družbenih skupin, odkrivati prostorske strukture oziroma funkcijske prostore, znotraj katerih se odvijajo temeljne in prostorsko relevatne družbene dejavnosti. Odpirata se dva sočasna prostorska koncepta : prvi posveča večjo pozornost strukturnim socialnogeografskim aspektom, drugi procesom v socialnogeografskih okoljih (Maier et al., 1977). 
Nemška oziroma srednjeevropska socialnogeografska šola je $s$ ponujenim raziskovalnim modelom dejansko poskusila opraviti novo sintezo med sektorskimi geografskimi panogami ne le v okviru same družbene geografije, ampak tudi v iskanju vzročno-posledičnih povezav med fizičnim prostorom oziroma fizičnogeografskimi danostmi in družbenimi elementi $\mathrm{v}$ tem prostoru ter njihovo razvojno dinamiko. Poseben poudarek je namenjala določevanju socialnih grup, pri čemer je še zlasti iskala povezave med kulturnogeografskimi vidiki obravnave skupnega načina življenja in določevanja vedenjskih skupnosti ter sociološkimi in ekonomskogeografskimi vidiki odkrivanja funkcijskih družbenih skupin, hkrati pa proučevanju socialnogeografskega prostora, $\mathrm{v}$ katerem je prav tako iskala povezave med kulturnogeografskimi in ekonomskogeografskimi elementi $v$ določevanju akcijskih radijev posameznih družbenih skupin, raziskovanju součinkovanja med družbenimi načeli persistence in inovacije ter opredeljevaju indikatorjev razvojne dinamike.

Zgoraj opisani raziskovalni pristop je seveda zaradi svoje obsežnosti in zahtevnosti bil na konkretnih primerih žal le delno uresničen, njegovi funkcijski in strukturnoanalitični vidiki pa so našli obilo aplikativnih možnosti v prostorskem planiranju družbenih in ekonomskih dejavnosti, v zadnjem času zlasti $v$ integrativnem družbenem, ekonomskem in prostorskem načrtovanju obmejnih in prekomejnih regij med Nemčijo in sosednjimi državami, kjer so socialni geografi bistveno prispevali k oblikovanju metodologije uresničevanja tako imenovanih evroregij. Če se je torej v nemškem govornem prostoru socialna geografija večinoma podredila aktualnim aplikativnim planskim zahtevam, obravnavata $\mathrm{v}$ severnoameriškem in severnoevropskem prostoru njene vsebine - povečini ločeno - bolj kvantitativno usmerjena socialnoekonomska geografija ter bolj kvalitativno usmerjena kulturna geografija ; slednja ohranja posebno mesto in tradicijo tudi v Franciji. Na podoben način so se tudi $v$ Sloveniji posamezna socialnogeografska sektorska področja razvijala večidel samostojno in le delno udejanila izvorno enotna raziskovalna načela. $\mathrm{V}$ vseh teh okoljih se je $\mathrm{v}$ zadnjih letih močneje uveljavila politična geografija, ki ponuja sintetičen vpogled $v$ družbene procese in prostorsko preobrazbo. Slednja pojmuje "polis" v najširšem kulturnem in družbenem pogledu in s tem proučuje prostorske vidike družbenih nasprotij prepletanj in sožitja med nosilci posebnih interesov na različnih družbenih in političnih ravneh ter različnih družbenih, kulturnih in političnih področjih. $\mathrm{V}$ tem oziru se prostorsko-regionalni razvoj ponovno postavlja $\mathrm{v}$ neposredno zvezo s kulturno in družbeno specifiko njihovih akterjev, se pravi, da se $\mathrm{v}$ marsikaterem pogledu srečujemo s sistemskim nastavkom, ki ga je pred približno tremi desetletji že ponudila "kontinentalna" socialna geografija.

Vzrok, da teh vidikov socialna geografija ni uspela povsem razrešiti in se je pretežno posvetila funkcijsko-strukturnim družbenim in prostorskim vsebinam, gre najverjetneje iskati v dejstvu, da je bil to čas intenzivne industrializacije, za ta proces pa je značilna zlasti deteritorializacija s centralizacijo in homogenizacijo. Temu nasprotno se sodobna, tako imenovana po-industrijska družba uveljavlja $\mathrm{z}$ decentralizacijo oblasti ter družbenih in ekonomskih dejavnosti, kar ponovno osmišlja 
teritorialno in regionalno dimenzijo, kulturne pokrajine ter regionalne družbene in kulturne elemente. $\mathrm{K}$ takemu razvoju prispevajo procesi socialne urbanizacije, izboljšanja izobrazbene ravni, razvoja terciarnih dejavnosti in komunikacijskih možnosti, mednarodna integracija in širjenje inovacijskih dejavnosti $v$ celotnem prostoru ter valorizacija kulturnih in etničnih posebnosti. Sodobna politična geografija na ta način vključuje pri svojih obravnavah tako politološko nadgradnjo, kot konkretne regionalne aspekte in združuje poleg geografskega tudi historične, ekonomske, socialne in politične plati obravnavane problematike. Iz tega izhaja spoznanje o spremenljivosti ali diferenciranosti odnosa prostor-družba, saj je lahko ta različen ne le $\mathrm{v}$ različnih časovnih obdobjih, ampak tudi $\mathrm{v}$ istem času in okolju. Tako lahko shajajo različni vedenjski sistemi, kakršne predstavlja na primer neenaka zakonodaja za avtohtono in neavtohtono prebivalstvo. Ob relativnosti družbenih in prostorskih pojavov se poudarjajo marsikdaj sočasni trajnejši vedenjski vzorci, ki jih posamezne družbene skupine iz lastne kulturne sfere prenašajo $v$ družbene in prostorske sisteme.

Pomembna področja raziskovanja poltičnogeografskih pojavov in preizkušanja sposobnosti sinteze te geografske panoge zadevajo problematiko odnosov med centri in periferijo ter med večinskimi in manjšinskimi družbenimi skupinami, kamor sodijo tudi obravnave različnih vidikov družbene in prostorske identitete, od regionalizma do nacionalizma ter obmejnosti. Ugotovljeni so bili različni elementi, ki tvorijo identiteto : miti in simboli, zgodovina in institucije ter prostor, kar skupno prispeva $\mathrm{k}$ oblikovanju posebnih kulturnih okolij, tako $\mathrm{v}$ družbenem kot prostorskem smislu. Jezik kot sredstvo komunikacije znotraj skupine in diferenciacije do ostalih družbenih skupin je nedvomno najbolj prodoren in značilen izraz različnosti. Zaradi tega je $v$ okviru odnosa center-periferija zelo pomembno vprašanje javnega priznanja oziroma legitimizacije jezikovnih standardov. Če po eni strani namreč javno nepriznavanje nekega jezika vpliva na njegovo razširjenost na individualni ravni, pa je po drugi strani raba določenega jezika kolektivna manifestacija, ki dobi v konfliktnih situacijah pomembno politično razsežnost. $\mathrm{V}$ tem smislu se $\mathrm{v}$ različnih okoljih lahko razvijejo različne tipologije jezikovnega razvoja, ki predstavljajo obenem različne tipologije odnosa med večinami in manjšinami ter med centri in periferijami. Te tipologije gredo od primerov "zmagoslavnih" centrov, kjer se centralni državni jeziki uveljavljajo na škodo perifernih, preko večjezičnih struktur, ki so značilne za federalizirane politične enote, do primerov "zmagoslavnih" periferij, ki ohranjajo ali uveljavljajo lastne ločene jezikovne standarde $v$ svojem družbenem okolju. Vmesne primere predstavljajo različne stopnje jezikovne standardizacije perifernih jezikov in različni odnosi med večjimi jezikovnimi skupnostmi.

Omenjene vidike je politična geografija obravnavala zlasti $v$ osemdesetih letih pod vplivom sistemske teorije, medtem ko je danes mimo politoloških in socioloških vplivov bolj zaznavno usmerjanje $h$ kvalitativnim družboslovnim in humanističnim vedam, h katerim bi lahko prištevali sociolingvistiko in sociopsihologijo. Ta prehod je morda najbolj izrazit pri razvoju tako imenovane vedenjske geografske šole, ki je izhajala iz sistemskih konceptov pri proučevanju sožitja med naravnimi in družbenimi 
elementi prostora in se nato posvetila raziskovanju prostorskih vedenjskih vzorcev posameznih socialnih skupin. Opravljen je bil zanimiv zasuk : v ospredju zanimanja niso več neke generične, abstraktne družbene skupine ter prav tako generične, abstraktne "regije", temveč posamezne konkretne socialne grupe in njihova specifična, konkretna življenska okolja, ki na ta način prevzemajo vlogo posebnih družbenih in kulturnih prostorov.

Nedvomno so spremembe $\mathrm{v}$ raziskovalnih konceptih ponovno približale prej veliko bolj neenotne družbene geografe, saj so vse spet potisnile nazaj "na teren". V takih razmerah dobiva ponovno veljavo tudi dobro razvita socialnogeografska metodologija terenskega dela in njena sposobnost zaznavanja različnih prostorsko pomembnih družbenih dejavnosti ter funkcionalnih zvez med posameznimi socialnimi grupami in njihovim življenskim prostorom. Poglavitno "novost" predstavlja verjetno bolj poudarjeno kulturno-geografsko vrednotenje in relativiziranje samega prostora pri odkrivanju elementov teritorialnega vedenja socialnih grup in interpretaciji družbenih in prostorskih dimenzij posameznih regij. Pri večini sodobnih družbenogeografskih raziskav so na ta način močno poudarjeni kvalitativni vidiki, ki postavljajo človeka $\mathrm{v}$ ospredje družbenih in prostorskih pojavov in procesov. In ta "humanizacija" družbene geografije je morda še najbolj dobrodošla pri proučevanju manjšin, lokalnih skupnosti ter obmejnih območij, se pravi vseh tistih stičnih prostorov, ki predstavljajo po eni strani potencialno konfliktno družbeno okolje, po drugi strani pa okolje, v katerem se udejanjajo nove integracije ob ohranjanju za Evropo tako značilne kulturne raznolikosti.

\section{IZKUŠNJE IN USPEHI SLOVENSKE SOCIALNE IN POLITIČNE GEOGRAFIJE PRI OBRAVNAVI MANJŠINSKE PROBLEMATIKE}

Slovenska socialna geografija je na pobudo prof. Vladimirja Klemenčiča združila klasični strukturno-analitični koncept obravnave manjšinske problematike, ki so ga razvili zlasti slovenski zgodovinarji po drugi svetovni vojni, z dinamičnim, procesološkim konceptom. Prvi pogled se je izražal zlasti v kritičnih pretresih popisnih podatkov glede na narodnostno pripadnost na avstrijskem Koroškem (Klemenčič, 1960 in 1976), ki pa ga je isti avtor kmalu obogatil z vnosom družbene in prostorske dinamike (Klemenčič, 1971). V tem pogledu so bili izpostavljeni procesi industrializacije in socialnega prestrukturiranja ter njihovi vplivi na narodnostno strukturo $\mathrm{v}$ etnično mešanih okoljih, ki pa so bili le nakazani. Sledeč popisnim rezultatom so bila opredeljena tri razvojna obdobja oziroma razdobja razkroja klasične agrarne strukture in uveljavljanja industrijske družbe: prvo označuje zlasti izseljevanje $v$ bolj oddaljene kraje, drugo (1934-1951) razvoj regionalnih središč Celovca in Beljaka, ki je prineslo demografsko erozijo, ne pa socialnega preoblikovanja na etnično mešanem podeželju, ter zadnje obdobje $\mathrm{z}$ uveljavljanjem 
turističnih dejavnosti na podeželju in možnostjo dopolnilnih dohodkov ter intenzivnih socialnih transformacij.

Socialnogeografski koncept pri obravnavi narodnih manjšin se je uspešno razvijal zlasti v sedemdesetih letih, ko je prevzel tudi nekatere nove prostorske in družbene elemente obmejnosti. S proučevanjem razvoja modernih prostorskih struktur je namreč postalo jasno, da je $\mathrm{v}$ družbenem in prostorskem pogledu bolj dinamičnih obmejnih območjih, kakršen je južni del današnje slovensko-italijanske meje med Gorico in Koprom, ob motorizaciji in mehanizaciji kmetijske proizvodnje odigrala v procesu suburbanizacije pomembno vlogo tudi odprtost meje (Klemenčič, 1992a). Prvi mednarodno odmeven članek na to temo je izšel že leta 1973 (Jeršič, Klemenčič, 1973) kot rezultat sodelovanja med Inštitutom oziroma Oddelkom za geografijo Univerze $v$ Ljubljani in Inštitutom za mednarodno sociologijo v Gorici, ki je leto poprej $\mathrm{v}$ tem mestu priredil mednarodni posvet o problemih in perspektivah obmejnih regij. Ob količinskem pregledu strukture in intenzivnosti prekomejnega prometa Slovenije s sosednjimi deželami je članek podal zanimivo analizo prostorsko relevantnih družbenih dejavnosti $v$ prekomejnem gibanju in povezovanju ter tako $\mathrm{v}$ slovenskem prostoru prvič apliciral socialnogeografsko metodologijo pri obravnavi obmejnih regij. Posebno pozornost je namenil vprašanjem oskrbe, izobraževanja, rekreacije in dela ter analizi prekomejnih tokov in vplivov na teh področjih. $\mathrm{Na}$ ta način je bila ugotovljena pomembna funkcija obmejnega prebivalstva v pospeševanju integracijskih procesov, zlasti še pomen znanja jezika sosednjega območja kot pospeševalca gospodarskega razvoja. Ker so narodne manjšine najbolj dejavne dvojezične skupnosti $v$ obmejnih prostorih, se članek končuje s sklepom, da je uresničevanje pravic narodnih skupnosti hkrati pomemben doprinos $\mathrm{k}$ družbenemu in ekonomskemu utrjevanju obmejnih regij, v katerih so le-te prisotne, saj lahko v takih razmerah narodne manjšine polneje izvajajo svojo naravno funkcijo prekomejnih povezovalcev oziroma oblikovalcev "odprtih obmejnih con".

Ta vidik varovanja narodnih manjšin $v$ funkciji regionalnega prostorskega in družbeno-ekonomskega razvoja ter prekomejne integracije je Klemenčič razvil že v naslednjih letih ob priliki mednarodne konference o manjšinah (Klemenčič, 1979), ki jo je priredila Tržaška pokrajina leta 1974, in med katero je vodil tudi ekspertno komisijo za družbeno-ekonomske probleme manjšin, ter ob priliki simpozija o socioekonomskih in prostorskih problemih Slovencev v Italiji, ki se je odvijal leta 1978, in za katerega je s Karlom Šiškovičem pripravil daljše uvodno poročilo (Klemenčič, Šiškovič, 1979).

V poročilu za tržaško manjšinsko konferenco, ki je obenem predstavljala pomembno vzpodbudo za slovensko manjšino $\mathrm{v}$ Italiji, da $\mathrm{v}$ sodelovanju $\mathrm{s}$ slovenskimi strokovnjaki ustanovi lasten dokumentacijsko-raziskovalni center, kasnejši Slovenski raziskovalni inštitut, je Klemenčič podrobneje obravnaval procese urbanizacije etnično mešanih in obmejnih območij, pri katerih tradicionalno agrarne manjšinske skupnosti vstopajo $\mathrm{v}$ urbane družbene in prostorske strukture. Ta proces odpira zato vprašanje enakopravne rabe jezika manjšin $\mathrm{v}$ vrsti temeljnih urbanih dejavnosti, kot so delo, izobraževanje, kultura in socialne storitve, administracija, gospodarstvo in 
rekreacija. Avtor je videl rešitev v globalni zaščiti nacionalnih manjšin, ki vključuje uvedbo dvojezične prakse na celotnem manjšinskem poselitvenem ozemlju. Poleg osnovne tipologije manjšinskih skupnosti vsebuje poročilo tudi zanimivo razvojno interpretacijo teh skupnosti $\mathrm{v}$ procesu urbanizacije in posledičnim uveljavljanjem dominantnega, večinskega jezika preko javnih institucij in urbanih družbenih dejavnosti. V prvi fazi urbanizacije prihaja tako do migracij iz tradicionalno agrarnih manjšinskih okolij $\mathrm{v}$ mesta, ki pa jih spremlja sprotno asimilacijsko utapljanje, medtem ko ostajata zaradi skromnih medsebojnih interakcij urbano (večinsko) in podeželsko (manjšinsko) okolje etnično homogena. V drugi fazi se $\mathrm{z}$ ekspanzijo urbanih dejavnosti in družbene strukture prične širjenje vpliva dominantne, večinske skupnosti $v$ mestno zaledje, ki se še poveča $\mathrm{v}$ tretji fazi, ko urbane strukture "prevzemajo" zaradi deagrarizacije in depopulacije izpraznjena mestna okolja in jih preoblikujejo $\mathrm{v}$ rekreacijske in bivalne prostore. $\mathrm{Na}$ ta način prihaja do objektivnega širjenja večinskega ozemlja oziroma prostora, $v$ katerem ima večina dominanten vpliv, manjšina pa izgublja nadzor nad svojim avtohtonim naselitvenim ozemljem, zaradi česar potrebuje posebne varovalne instrumente, ki naj ji omogočajo enakovrednejšo jezikovno zastopanost $v$ sodobnih urbanih dejavnostih in javnih institucijah.

V skupnem prispevku za zbornik Slovenskega raziskovalnega inštituta sta vprašanje učinkovite zaščite narodnih manjšin, ki naj upošteva in vsebuje ne le jezikovnokulturne, pač pa tudi socialnoekonomske in prostorske manjšinske posebne potrebe, podrobneje obravnavala Klemenčič in Šiškovič. Avtorja sta v tem oziru identificirala dva osnovna in sočasna tipa razvojnih procesov : procese, ki narodno manjšino vse bolj odtujujejo matičnemu narodu, in procese, ki isto manjšino vse bolj približujejo večinskemu narodu. Ker se ti procesi naslanjajo na razvojne inovacijske dejavnike industrializacije ter prostorskega odtujevanja avtohtonega ozemlja, se članek končuje $\mathrm{z}$ ugotovitvijo, da mora večinska oblast manjšinam dodeliti večjo avtonomijo, ki naj nadomesti izgubo popolnega nadzora nad naselitvenim teritorijem, in ustrezne protivrednosti, ki naj omejujejo socialnoekonomska razvojna neskladja med večinskim prebivalstvom in manjšinsko skupnostjo.

Ne glede na večje ali manjše aktualnopolitične povezave, do katerih je proučevanje manjšinske problematike velikokrat nagnjeno, so raziskovalni nastavki iz sedemdesetih let vendarle odprli vsaj dvoje pomembnejših področij : prvo je šlo v smer poglabljanja teoretičnih vidikov manjšinske stvarnosti, drugo pa v umeščanje manjšinskih razvojnih vidikov $\mathrm{v}$ konkretno regionalno stvarnost. Prvi sklop je najpogosteje postavljal manjšine $\mathrm{v}$ širši srednjeevropski okvir in prispeval zlasti $\mathrm{k}$ uveljavljanju same manjšinske problematike, za katero so se posebno zavzeli slovenski predstavniki v okviru mednarodnih asociacij, kot je delovna skupnost AlpeJadran, a tudi $v$ okviru mednarodnih geografskih združenj. Pomemben rezultat dejavnosti slovenskih strokovnjakov in geografov, med temi pa zlasti Klemenčiča in njegovih sodelavcev, na tem področju sta dva pomembna mednarodna simpozija, ki sta se odvijala na Slovenskem leta 1993, in sicer simpozij "Geografija in narodnosti" pod okriljem Komisije za prebivalstvena vprašanja pri Mednarodnem združenju geografov ter simpozij "Manjšine v prostoru Alpe-Jadran" pod okriljem vlade 
Republike Slovenije in Delovne skupine za manjšine Alpe-Jadran. Za oba simpozija je Klemenčič pripravil uvodna referata (Klemenčič, 1993a in 1994a), v katerih je izpostavil temeljne historične in politične vidike srednjeevropskega prostora $\mathrm{s}$ prepletanjem enonacionalnih in nacionalno mešanih območij ter pogostim spreminjanjem poteka političnih meja. Na nacionalno strukturo oziroma na dinamiko uveljavljanja različnih faz njenega preoblikovanja so tako po avtorjevem mnenju vplivale vojne $v$ težnji po spreminjanju državnih meja, spremembe državnih meja, razlike $v$ družbenopolitičnih sistemih ali doseženi stopnji socioekonomskega razvoja med sosednjima državama, odnos center-periferija $v$ okviru posameznih držav, večja ali manjša vključenost posameznih obmejnih območij v procese evropske integracije ter koncept varovanja identitete narodnih manjšin oziroma vprašanje odnosov med večinskim narodom in manjšinskimi nacionalnimi skupnostmi. Ta odnos se kaže že pri popisih prebivalstva po narodnosti, ki so praviloma nezanesljivi in mnogokrat celo povsem zakrivajo obstoj manjšin, a pogostoma predstavljajo tisto temeljno platformo, na katero se naslanjajo manjšinske zakonodaje $\mathrm{v}$ posameznih državah. Pomembno novost in vzpodbudo za obmejna območja in $v$ njih živeče narodne manjšine pa ponuja ravno $\mathrm{v}$ srednjeevropskem prostoru možnost intenzivneješega prekomejnega sodelovanja, ki blaži družbene in ekonomske razlike med obema stranema ter daje obmejnim skupnostim, še zlasti pa manjšinam, novo funkcijo povezovalcev sosednjih območij ob prilagajanju manjšinskih institucij na področju izobraževanja, kulture in infrastrukturnih dejavnosti, kar naj kompenzira dejstvo, da se tudi $\mathrm{v}$ manjšinskem avtohtonem naselitvenem ozemlju s priselitvijo večinskega prebivalstva uveljavlja model etnično mešanega prostora.

$\mathrm{S}$ tega področja je treba omeniti še Klemenčičev prispevek, ki obravnava problem narodnosti in narodnih manjšin $v$ procesu urbanizacije $\mathrm{z}$ vidika geografije in etnologije (Klemenčič, 1986a), v katerem avtor izpostavlja pomen interdisciplinarnosti pri proučevanju družbeno-ekonomskih procesov ter spreminjanja položaja in funkcije narodnih manjšin. Za geografe je zato potrebno poznati po eni strani fizične in družbene dejavnike, ki vplivajo na manjšine, po drugi strani pa učinke samih manjšin na geografsko okolje. Avtor še zlasti podčrtuje pomen proučevanja političnogeografskih vidikov etnično mešanih območij ter tendenc družbenoekonomskega razvoja, a tudi etnoloških proučevanj načina življenja prebivalstva v obmejnih in etnično mešanih okoljih, kjer je prišlo z razvojem urbane družbe do stopnjevanja narodnostne pomešanosti in nastopa procesa asimilacije.

$\mathrm{S}$ tako imenovanimi diahronimi vidiki preoblikovanja manjšinskih skupnosti se ukvarja še prispevek za etnično delavnico, ki je potekala med štirimi slovenskimi inštituti v začetku devetdesetih let (Bufon, 1990a). Ta poudarja tesno povezanost med raziskovanjem etnično mešanih območij in obmejnih območij, v katere se prve pogosto umeščajo. Iz te prepletenosti izhaja potreba po kompleksnem in multidisciplinarnem pristopu, ki naj med drugim upošteva vidike preoblikovanja odnosa center-periferija, same obmejne pokrajine $\mathrm{z}$ ozirom na mednarodne odnose, preoblikovanje manjšinske in celotne družbene strukture ter splošnih ekonomskih 
razmer, preoblikovanje medetničnih odnosov in hkrati rezultate njihovega medsebojnega součinkovanja.

Nekje v sredi med prvim, bolj teoretičnim, in drugim sklopom, ki črpa raziskovalne rezultate iz posameznih regionalnih stvarnosti, se uvrščajo prispevki slovenskih geografov, za katere je značilno, da teoretične izsledke aplicirajo na posameznih konkretnih regionalnih in manjšinskih stvarnostih, ali da iz teh stvarnosti s primerjalno metodo izpeljejo lastne, marsikdaj povsem originalne teoretične zaključke. Med taka dela sodijo na primer članki, ki dajejo pregled različnega položaja manjšin ter lokalnih skupnosti $\mathrm{v}$ okviru slovenskih in sosednjih obmejnih območjih in oceno njihove funkcije pri prekomejnih integracijskih procesih. V tem okviru se poudarjajo funkcijski socialnoekonomski in prostorski vidiki $\mathrm{v}$ luči socialno-ekonomske preobrazbe in uveljavljanja urbane družbe, ki jo opredeljuje tudi povečan prekomejni blagovni, osebni in informacijski pretok (Klemenčič, 1987a in 1994b; Zupančič, 1994a). Klemenčič med ovirami pri povezovanju družbenega razvoja, narodov in kultur različnih držav navaja iz preteklosti izvirajoče posledice zaprtega gospodarstva, se pravi perifernost obmejnih območij, ki pogojuje tudi nezadostno infrastrukturno in družbeno komunikacijo med sosednjimi območji, ter zapostavljanje jezika in kulture narodnostnih manjšin in njihovega socialnega položaja kot tretji dejavnik. Opažanja ob slovenskih mejah z Italijo, Avstrijo in Madžarsko potrjujejo, da spremlja izboljšanje socialne strukture manjšin tendenca po zmanjševanju števila njihovih pripadnikov oziroma asimilaciji. Tudi Zupančič je mnenja, da so elementi modernizacije bili pogosto orodje za asimilacijo manjšine in $\mathrm{s}$ tem za njihovo številčno nazadovanje. Zaradi asimilacije socialno in prostorsko najbolj mobilnih pripadnikov manjšine je imelo prizadevanje manjšin za izboljšanje lastnih socialnih in političnih razmer tudi značaj etnične stabilizacije. Ob pregledu stanja različnih obmejnih in manjšinskih situacij, katerim so sicer v bolj indirektni obliki namenjeni tudi drugi Klemenčičevi prispevki (Klemenčič, 1978 in 1987b), je ob ekonomskih in infrastrukturnih aspektih funkcionalne prekomejne povezanosti poudarjen še pomen funkcionalne dvojezičnosti oziroma dvojezičnega izobraževanja obmejnega prebivalstva kot družbenega integracijskega dejavnika, ki prispeva $\mathrm{k}$ izboljšanju položaja in vloge manjšin v lastnem regionalnem in prekomejnem prostoru (Hajos, Klemenčič, 1986; Klemenčič, 1984 in 1995; Klemenčič, Zupančič, 1995).

Manjšine lahko torej opredeljujemo kot poseben dejavnik v družbenem, ekonomskem in prostorskem razvoju, ki je tem bolj uspešen, kolikor bolj uveljavlja svoje kulturne posebnosti. Temu sodobnemu vidiku regionalnega razvoja so slovenski geografi pričeli posvečati več pozornosti $\vee$ zadnjih letih in po eni strani izpostavili funkcijo lokalnih skupnosti in narodnih manjšin v okviru družbene integracije med slovenskimi in sosednjimi obmejnimi območji (Bufon, 1996 ; Klemenčič, Bufon, 1994), po drugi pa na konkretnih primerih slovenskih manjšin izdelali nekatere modele etničnoregionalnega razvoja (Bufon, 1987, 1988 in 1992a) ali pa na primerih posameznih manjšin diskutirali nekatera teoretična izhodišča (Bufon, 1991a, 1992b, 1994a in 1994b). V ta okvir sodijo končno še poskusi povezovanja manjšinske in regionalne identitete na primeru različnih območij slovenskega etničnega ozemlja (Klemenčič, 
Zupančič, 1992), medtem ko so se manjšinskih vidikov dotaknili tudi prispevki, ki so se ukvarjali z novim geopolitičnim položajem Slovenije (Klemenčič, 1992b in 1993b; Klemenčič, Genorio, 1993).

Obdelano je bilo tako vprašanje terminologije avtohtonih narodnih manjšinskih skupnosti v povezavi $\mathrm{z}$ njihovim statusom ter družbeno in prostorsko funkcijo. V historičnem pogledu termin nacionalne manjšine implicitno opredeljuje te družbene skupine kot povsem identične $\mathrm{z}$ matičnim narodom, saj so te predstavljale nekakšen podaljšek matičnega naroda $v$ sosednjo državo in zaradi tega nemalokrat povzročale mednarodne konflikte in napetosti. Danes se te manjšine spričo družbene integracije v večinsko okolje uveljavljajo kot avtohtone etnične skupnosti $\mathrm{z}$ mednarodno razsežnostjo in izvajajo vrsto specifičnih družbenih in prostorskih funkcij, od narodno-obrambnih do regionalno-razvojnih. Obenem je proces modernizacije spreminjal prostorsko razmestitev etnične manjšine ter etnične strukture klasičnega ali historičnega majšinskega etničnega ozemlja zaradi povečane prostorske mobilnosti prebivalstva. $\mathrm{S}$ tem je $\mathrm{v}$ prostorskem pogledu uveljavil širjenje etnično mešanih območij in $v$ družbenem pogledu oblikovanje tako imenovanega etničnega kontinuuma $\mathrm{z}$ razkrojem tradicionalne etnične strukture. Kot posledico tega procesa so opravljene raziskave izpostavile izenačevanje socio-ekonomske strukture znotraj etnično mešanih območij, ovrednotenje kulturnih značilnosti pokrajine ter povečevanje lokalne in regionalne dejavnosti etničnih manjšin in lokalnih skupnosti pri ohranjanju kulturne pokrajine ter medregionalnem in mednarodnem povezovanju. Podrobneje so bile obdelane tudi faze etno-regionalnega razvoja, ki gredo od statičnega sožitja dvoje prostorsko zaprtih enot, se pravi agrarnega, etnično homogenega podeželja in predindustrijskih, etnično mešanih urbanih središč, preko faze enosmernih, labilnih inovacijskih procesov industrializacije in kasneje deagrarizacije, ki so $\mathrm{z}$ izseljevanjem $\mathrm{z}$ manjšinskega etničnega ozemlja $\mathrm{v}$ bližnja zaposlitvena območja dejansko razširili obseg narodnostno mešanega ozemlja, do faze formiranja prostorsko odprte in stabilne urbane družbe, kjer se brišejo tradicionalne družbene in etnične razlike med mesti in podeželjem, a kjer etnične manjšine dobivajo nove razvojne perspektive. $Z$ vidika ohranjanja etnične identitete je ravno vmesna faza inovacijskih procesov industrializacije in deagrarizacije najbolj kritična, čeprav ne povzroča takojšnjih strukturnih sprememb, a vodi po eni strani $k$ demografski eroziji avtohtonega manjšinskega ozemlja in v skrajni posledici do propada dela kulturne pokrajine, po drugi strani pa $\mathrm{k}$ dokaj konsistentnemu in celo kompatnemu širjenju manjšinskega prebivalstva izven lastnega avtohtonega ozemlja, kar ima spet lahko različne posledice. Depopulacija avtohtonega ozemlja je zaskrbljujoča tudi zato, ker temeljijo manjšinski normativno-varstveni ukrepi po ustaljeni praksi na historičnem teritorialnem principu, se pravi, da so omejeni na avtohtono naselitveno ozemlje, ki ima za pripadnike manjšine obenem pomembno identifikacijsko vlogo, zaradi česar lahko pomeni umik s tega ozemlja mnogokrat tudi izgubo lastne kulturne vsebine. Po drugi strani pa lahko prav izseljeniška izkušnja z neposrednim stikom z drugimi etničnimi skupinami prispeva k odkrivanju lastne etnične in kulturne "različnosti" in s tem h krepitvi ali celo porajanju narodnostne zavesti. Uveljavljanje "etničnega 
kontinuuma" tudi v nekdaj etnično homogenem manjšinskem prostoru, ki ga prinaša sodobna družbena urbanizacija s porastom prostorske mobilnosti, pa ne vodi nujno $\mathrm{v}$ asimilacijo pripadnikov manjšine ali nastop tako imenovanega vindišarstva, saj se $\mathrm{s}$ tem oblikuje povsem nov tip etnične skupine, ki ni le rezultat asimilacijskega stapljanja, temveč aktivne etnične integracije. Na tej osnovi se v etnično mešanih in obmejnih prostorih uveljavlja družbeni multikulturalizem, ki omogoča strpnejše medetnične odnose, pa tudi intenzivnejše oblike prekomejnega povezovanja.

Poslednji, a verjetno tudi najbolj obsežen sklop obravnav manjšinskih vidikov, ki so jih opravili slovenski geografi, zadeva regionalno izraziteje naravnane študije. Te izhajajo iz analize konkretnih narodno-manjšinskih stvarnosti in, ker so slednje $v$ obmejnih prostorih, večkrat sovpadajo s pregledom regionalne strukture posameznih obmejnih in etnično mešanih območij. V tem pogledu se srečujemo tudi z nekaterimi zanimivimi komparativnimi socialnogeografskimi predstavitvami, ki povezujejo položaje manjšin na obeh straneh meje (Klemenčič, 1975a; Valussi, Klemenčič, 1978) ali različnih manjšin znotraj slovenskega prostora (Klemenčič, 1985 in 1990). Iz različnih zornih kotov so bili tako obdelani vidiki položaja, preoblikovanja in odprtih družbenih in prostorskih problemov Slovencev v Italiji (Bufon, 1990b, 1991b in 1991c ; Klemenčič, 1977 in 1996), deloma tudi v povezavi z razvojem prekomejnih integracijskih procesov (Bufon, 1995; Klemenčič, 1974; Klemenčič, Bufon, 1991 ; Klemenčič, Piry, 1982). Pri koroških Slovencih je bila posebna pozornost namenjena problemom etnične identitete in njenega ohranjanja v razmerah družbenoekonomskega razvoja (Klemenčič, 1986b; Klemenčič V., Klemenčič M., 1984; Steinicke, Zupančič, 1995 ; Zupančič, 1993a, 1993b in 1994b), medtem ko je posebna zasluga prof. Klemenčiča tudi ta, da se je pričelo $\mathrm{z}$ intenzivnejšem proučevanjem položaja slovenske manjšine na avstrijskem Štajerskem (Klemenčič, 1994c). Dokaj podrobno so bili po zaslugi mladinskih socialnogeografskih raziskovalnih taborov, ki jih na pobudo Klemenčiča neprekinjeno od leta 1972 v tem delu Slovenije prireja Inštitut za geografijo, obdelani demografski, socialni in etnični problemi madžarske manjšine $v$ Prekmurju $v$ povezavi $s$ tukajšnjimi splošnimi vidiki demografsko ogroženega in nerazvitega območja (Klemenčič, 1991; Olas et al., 1985; ZOTKS, 1981 ; Zupančič, 1991, 1993c in 1995). Slabo zastopana ali docela odsotna pa je v obravnavah slovenskih geografov problematika porabskih Slovencev (Olas, 1973 in 1991). Določeno pozornost so vzbujali tudi demografski problemi italijanske manjšine ter vidiki funkcionalne dvojezičnosti $v$ etnično mešanem prostoru Slovenske Istre v pogojih urbane družbe in razvoja prekomejnih funkcionalnih vezi s sosednjo Italijo (Klemenčič, 1975b, 1986c in 1990b; Piry, Repolusk, 1985; Repolusk, 1990 in 1991). Po osamosvojitvi Slovenije in Hrvaške so se slovenski geografi spopadli še z vprašanjem etničnih, kulturnih in regionalnih povezav in transformacij na območju Istre ter s problemi identifikacije slovenske etnične skupnosti na Hrvaškem (Bufon, 1993; Repolusk, 1995 ; Zupančič, Repolusk, 1995).

Kot poseben sklop velja vsaj na kratko omeniti še marsikdaj pionirsko delo, ki so ga slovenski geografi opravili pri proučevanju slovenskega etnosa v diaspori (Genorio, 1989 in 1992) ter problematike tako imenovanih "novih manjšin" oziroma 
neavtohtonih etničnih skupin in nemških staroselcev v Sloveniji (Gosar, 1993 ; Klemenčič, 1988; Kokole, 1986; Pak, 1993), čeprav so se v slednjem primeru redkeje posluževali raziskovalno-interpretativnih možnostih, ki jih ponuja socialnogeografska metodologija terenskega dela.

\section{SKLEP}

Iz opravljenega pregleda rezultatov slovenskega socialnogeografskega in političnogeografskega proučevanja manjšinske problematika izhaja ne le količinska obsežnost, ki potrjuje dejstvo, da so slovenski geografi po zaslugi Vladimirja Klemenčiča to tematsko področje razvili $v$ enega pomembnejših raziskovalnih sklopov nacionalnega strokovnega interesa, temveč tudi kvalitativna naravnanost večine prispevkov. Ti so že razmeroma zgodaj opustili faktografsko-deskriptivni model, ki še danes preveva marsikatero sorodno delo $\mathrm{v}$ drugih geografskih okoljih, in manjšinsko ter sploh etnično-nacionalno problematiko postavili v okvir širše dinamike spreminjanja družbenih, ekonomskih in prostorskih elementov. $\mathrm{V}$ tem smislu so bila vzporedno ali celo sočasno poglobljena spoznanja o manjšinski socioekonomski strukturi in njeni transformaciji $\mathrm{v}$ odnosu do etnične identitete ter družbene in prostorske funkcije majšinske skupnosti v okviru lastnega naselitvenega ozemlja in $\mathrm{v}$ prekomejnih povezavah. Ravno kompleksnost tovrstnega pristopa in analitična ter sintetična poglobljenost socialnogeografskih vidikov predstavlja verjetno najbolj originalni prispevek slovenske geografije mednarodni strokovni javnosti, ki se na njeno metodologijo in raziskovalne rezultate večkrat sklicuje, zlasti glede prostorske aktivnosti lokalnih skupnosti in obmejnih manjšin. Raziskovalni napori na področju proučevanja sožitja in povezave $v$ etnično mešanih in obmejnih območjih, ki navsezadnje niso značilni le za slovenski prostor, temveč za velik del našega kontinenta, so tako nedvomno prispevali k širši afirmaciji Slovenije in slovenske znanosti ter njenih dosežkov. Ob tem pa ostajajo odprta in skorajda neraziskana še številna vprašanja neavtohtonih etničnih skupin, ki predstavljajo prav tako značilen element slovenskega socialnega in političnogeografskega okolja, kakor tudi razni odnosi med lokalnimi, regionalnimi, etničnimi in nacionalnimi identitetami in njihov vpliv na življenje in prostorsko organizacijo različnih socialnih skupin, skratka vprašanja ohranjanja izvorne teritorialne in kulturne identitete $v$ pogojih vse večje družbene in strukturne mednarodne integracije. Vse to predstavlja nov izziv in nove perspektive za socialno in politično geografijo v Sloveniji in v svetu. 


\section{LITERATURA}

- Bufon M.,1987: Regionalni razvoj in narodnostno vprašanje. Geografski obzornik 2, str. 85-87 .

- Bufon M., 1988: Sviluppo regionale e sviluppo etnico : il caso degli Sloveni in Italia, V : L'effet frontière dans les Alpes, Tome I, St.Vincent, str. 54-61 .

- Bufon M., 1990a: Etničnost in teritorialnost ali geografija med disciplinarno in multidisciplinarno razsežnostjo. Razprave in gradivo 23, str. 129-131.

- Bufon M., 1990b: Nove "meje" slovenske etnične skupnosti v Italiji. Teorija in praksa 12, str. 1580-1589.

- Bufon M., 1991a: Prispevek k sistematizaciji geografskega proučevanja nacionalnih manjšin na primeru Slovencev v Italiji. Geografija v šoli 1, str. 26-28 .

- Bufon M., 199lb: Temeljni problemi geografskega proučevanja etničnih manjšin na primeru Slovencev v Italiji. Geografski vestnik 62, str. 99-111 .

- Bufon M., 1991c: Un caso di identita etnica e territoriale : gli Sloveni in Italia. Rivista Geografica Italiana 98, str. 437-454 .

- Bufon M., 1992a :Prostorska opredeljenost in narodna pripadnost - Obmejna in etnično mešana območja $v$ evropskih razvojnih silnicah : primer Slovencev $v$ Italiji. Trst.

- Bufon M., 1992b: Sedanji evropski razvojni procesi in varstvo manjšin : stari problemi in nove perspektive v luči politične geografije. Geografija v šoli 2, str. 25-32.

- Bufon M., 1993:Istra : novi problemi starih regij. Annales 3, str. 197-202 .

- Bufon M., 1994a: Manjšine v sodobnih razvojnih procesih : primer Slovencev v Italiji. V : P.Vencelj, V.Klemenčič in S.Novak Lukanovič (ur.), Manjšine v prostoru Alpe-Jadran, Ljubljana, str. 52-69.

- Bufón M., 1994b :Nacionalne manjšine in njihova funkcija $v$ mednarodnih integrativnih procesih : iluzija ali realnost. V : I.Štrukelj in E.Sussi (ur.), Narodne manjšine danes in jutri, Trst, str. 87-95.

- Bufon M., 1995: Prostor, meje, ljudje - razvoj prekomejnih odnosov, struktura obmejnega območja in vrednotenje obmejnosti na Goriškem. Trst.

- Bufon M., 1996: Some political-geographical problems of transition in Central. Europe : the case of Slovenia.V: F.W.Carter, P.Jordan in V.Rey (ur.), Central Europe after the Fall of the Iron Curtain, Wiener Osteuropa Studien 4, Frankfurt, str. 73-89. 
- Genorio R., 1989: Slovenci v Kanadi. Geographica Slovenica 17.

- Genorio R., 1992: Socialnogeografske značilnosti razvoja poselitve Slovencev v Buenos Airesu. Geographica Slovenica 23, str. 423-438.

- Gosar A., Narodnosti Slovenije - spreminjanje etnične podobe v Srednji Evropi. Geographica Slovenica 24, 1993, str. 33-50 ;

- Hajos F., Klemenčič V., 1986: Dvojezičnost v Sloveniji. Geografski obzornik 33, str. 86-95.

- Jeršič M., Klemenčič V., 1973: Topical problems of open boundaries : the case of Slovenia: V: R.Strassoldo (ur.), Confini e regioni/Boundaries and Regions, Trieste, str. 123-133.

- Klemenčič V., 1960: Kritični pretres avstrijskega popisa 1951 z ozirom na jezikovno strukturo na Koroškem Razprave in gradivo 2, str. 101-182 .

- Klemenčič V., 1971: Spreminjanje gospodarske in socialne strukture in narodnostni problemi Slovencev na južnem Koroškem. V: V.Klemenčič (ur.), Koroška in koroški Slovenci, Maribor, str. 60-69.

- Klemenčič V., 1974: Odprta meja med Jugoslavijo in Italijo in vloga manjšin: Teorija in praksa 9-10, str. 65-72.

- Klemenčič V., 1975a : Slovenska in italijanska narodna manjšina v luči urbanizacije in odprte jugoslovansko-italijanske državne meje. V: Slovenci v Italiji po drugi svetovni vojni, Ljubljana, str. 505-515.

- Klemenčič V., 1975b: Italijansko prebivalstvo na narodnostno mešanem ozemlju na Koprskem v SR Sloveniji. V: Slovenci v Italiji po drugi svetovni vojni, Ljubljana, str. 517-525.

- Klemenčič V., 1976: Kritika uradnih avstrijskih popisov prebivalstva v letih 1951, 1961 in 1971 glede na slovensko manjšino in slovenščino kot občevalni jezik. Razprave in gradivo 7-8, str. 101-124.

- Klemenčič V., 1977: Regionalna preobrazba s Slovenci poseljenega območja ob italijansko-jugoslovanski meji v Italiji. Geografski vestnik 49, str. 149-156.

- Klemenčič V., 1978: Grenzregionen und nationale Minderheiten. Geographica Slovenica 8, str. 7-20.

- Klemenčič V., 1979: Urbanizzazione spaziale e minoranze etniche nel Centro Europa V: Provincia di Trieste, Conferenza Internazionale sulle minoranze 10-14 luglio 1974, Atti della Conferenza I, Trieste, str. 59-69.

- Klemenčič V., 1984: Funkcija in položaj jezika Slovencev v zamejstvu ter narodnosti v SR Sloveniji V: Dvojezičnost - individualne in družbene razsežnosti, Ljubljana, str. 27-32. 
- Klemenčič V., 1985: Položaj italijanske in madžarske narodnosti in narodnostno mešana območja v slovenski Istri in Prekmurju v luči socialne geografije. Geographica Slovenica 16, str. 7-11.

- Klemenčič V., 1986a: Problem narodnosti in narodnostnih manjšin v procesu urbanizacije z vidika geografije in etnologije. Dela 3, str. 45-53.

- Klemenčič V., 1986b: Koroški Slovenci danes. Geografski obzornik 23, str. 51-57.

- Klemenčič V., 1986c: Italijansko prebivalstvo na narodnostno mešanem ozemlju na Koprskem v SR Sloveniji. Geografski obzornik 33, str. 96-101.

- Klemenčič V., 1987a: Socialno-ekonomske in prostorske funkcije narodnostne pomešanosti Slovencev kot manjšine $\mathrm{v}$ sosednjih državah ter Madžarov in Italijanov v SR Sloveniji. Geografski obzornik 2, str. 81-84.

- Klemenčič V., 1987b: Državna meja na območju SR Slovenije in obmejna območja kot nov geografski fenomen. Razprave in gradivo 20, str. 57-79.

- Klemenčič, V., 1988: Die Deutschen in der Statistik des jugoslawischen Slowenien zwischen den beiden Weltkriegen. V: Geschichte der Deutschen im Bereich des heutigen Slowenien 1848-1941, Schriftenreihe des Oesterreichen Ostund Suedosteuropa Instituts 13, str. 241-247.

- Klemenčič V., 1990a: Sodobni regionalni problemi madžarske in italijanske manjšine v procesih družbenoekonomske preobrazbe. Razprave in gradivo 24 , str. 52-61.

- Klemenčič V., 1990b: Koprsko kot obmejno, narodnostno mešano in terciarizirano območje V: Primorje - zbornik 15. zborovanja slovenskih geografov, Portorož, str. 99-105.

- Klemenčič V., 1991: Prekmurje kot nerazvito obmejno območje v Sloveniji. Dela 8, str. 108-124.

- Klemenčič V., 1992a: Slovenija in Slovenci danes ter jutri v luči socialne geografije. Geographica Slovenica 23, str. 37-58.

- Klemenčič V., 1992b: Geopolitični položaj Slovenije in njena odprtost v Evropo. Geografija v šoli 2, str. 15-24.

- Klemenčič V., 1993a: Narodne manjšine kot element demografske in prostorske stvarnosti v alpsko-jadransko-panonskem prostoru. Geographica Slovenica 24, str. 19-31.

- Klemenčič V., 1993b: Geopolitični položaj in regionalizem na primeru jugozahodne Slovenije. Annales 3, str. 203-210.

- Klemenčič V., 1994a: Narodne manjšine kot element politične, prostorske, socialne in ekonomske stvarnosti $\mathrm{v}$ alpsko-jadransko-panonskem prostoru V: P.Vencelj, V.Klemenčič in S.Novak Lukanovič (ur.), Manjšine v prostoru AlpeJadran, Ljubljana, str. 1-8. 
- Klemenčič V., 1994b: Funkcija narodnih manjšin v prekomejnem meddržavnem povezovanju in evropski integraciji V: I.Štrukelj in E.Sussi (ur.), Narodne manjšine danes in jutri, Trst, str. 97-107.

- Klemenčič V., 1994c: Ueberlebensmoeglichkeiten der nicht anerkennten Minderheit der Slowenen in der Steirmark. V: C.Stenner (ur.), Steirische Slowenen - Zweispraechigkeit zwischen Graz und Maribor, Graz, str. 81-90.

- Klemenčič V., 1995: Pomen slovenskega manjšinskega šolstva v sodobnih procesih evropske integracije. V: B.Lipužič (ur.), Čedermaci današnjega dne, Ljubljana, str. 11-29.

- Klemenčič V., 1996: Razvoj in položaj slovenske manjšine v Kanalski dolini v luči evropske integracije. V: I.Šumi in S.Venosi (ur.), Večjezičnost na evropskih mejah - primer Kanalske doline, Kanalska dolina, str. 59-75.

- Klemenčič V., Bufon M., 1991: Geographic problems of frontier regions : the case of the Italo-Yugoslav border landscape. V: D.Rumley in J.V.Minghi (ur.), The Geography of Border Landscapes, London, str. 86-103.

- Klemenčič V., Bufon M., 1994: Cultural elements of integration and transformation of border regions : the case of Slovenia. Political Geography 1, str. 73-83.

- Klemenčič V., Genorio R., 1993: The new state of Slovenia and its function within the frame of Europe. GeoJournal 3, , str. 323-335.

- Klemenčič V., Klemenčič M., 1984: Položaj slovenske manjšine na avstrijskem Koroškem v luči historičnih in socialnogeografskih procesov. V: Koroški Slovenci v Avstriji včeraj in danes, Ljubljana-Celovec, str. 95-111.

- Klemenčič V., Piry I., 1982: The elements of regional integration in border areas. V: R.Strassoldo in G.Delli Zotti (ur.), Cooperation and Conflict in Border Areas, Milano, str. 61-71.

- Klemenčič V., Šiškovič K., 1979: Considerazioni per la valutazione dei problemi socio-economici ed ambientali degli Sloveni in Italia. V: Atti del Simposio sui problemi socioeconomici e ambientali degli Sloveni in Italia, Volume I, Trieste, str. 5-21.

- Klemenčič V., Zupančič J., 1992: Regionalizem - nov izziv za geografijo : primer slovenskega etničnega ozemlja. Geografski vestnik 64, str. 157-168.

- Klemenčič V., Zupančič J., 1995: Functional bilingualism - an attempt to preserve the identity of national minorities (in case of Slovenia). V: K.Heffner in V.Klemenčič (ur.), Small Regions in United Europe - Macroregional and Social Policy, Opole, str. 19-27.

- Kokole V., 1986: Migracije v SR Slovenijo iz drugih republik in narodnostna sestava njenega prebivalstva. Geografski vestnik 58, str. 13-25. 
- Maier J., Paesler R., Ruppert K., Schaffer F., 1977: Sozialgeographie. Braunschweig.

- Olas L., 1973: Slovensko Porabje. Geografski obzornik 3-4, str. 15-20.

- Olas L., Genorio R., Repolusk P., Kladnik D., 1985: Narodnostno mešano območje v Prekmurju, Geographica Slovenica 16, str. 15-43.

- Olas L., 1991: Demografske razmere v Porabju. Geografija v šoli 1, str. 29-31.

- Pak M., 1993: Geografska problematika narodnostne sestave prebivalstva Ljubljane. Geographica Slovenica 24, str. 51-63.

- Piry I., Repolusk P., 1985: Narodnostno mešano območje v Slovenski Istri, Geographica Slovenica 16, str. 45-73.

- Repolusk P., 1990: Spreminjanje narodnostne strukture prebivalstva kot element demogeografskega razvoja $\vee$ Koprskem primorju. V: Primorje - zbornik 15. zborovanja slovenskih geografov, Portorož, str. 107-112.

- Repolusk P., 1991: Etnično-regionalni problemi italijanske narodnosti v Sloveniji. Geografija v šoli 1, str. 34-35.

- Repolusk P., 1995: Elementi prebivalstvenega razvoja v obmejnih hrvaških občinah s poudarkom na Slovencih. V: V.Kržišnik-Bukić (ur.), Slovenci v Hrvaški, Ljubljana, str. 261-284.

- Steinicke E., Zupančič J., 1995: Koroški Slovenci v luči sodobnih prostorskih, socialnih in političnih procesov. Razprave in gradivo 29-30, str. 111-126.

- Valussi G., Klemenčič V., 1978: Il confine aperto tra Italia e Jugoslavia e il ruolo delle minoranze. V: G.Valussi (ur.), Minoranze a confronto - contributi alla geografia delle minoranze etniche sui due lati della frontiera italo-jugoslava, Pubblicazioni dell'Istituto di Geografia della Facolta di lingue e letterature straniere dell'Universita di Udine, Udine, str. 19-31.

- ZOTKS, 1981: Gibanje "Znanost mladini", Mladinski socialno-geografski raziskovalni tabor v Prekmurju. Ljubljana.

- Zupančič J., 1991: Etničnoregionalni problemi madžarske manjšine v Prekmurju. Geografija v šoli 1, str. 32-33.

- Zupančič J., 1993a: Novejše spremembe v socialni strukturi koroških Slovencev. Razprave in gradivo 28, str. 115-123.

- Zupančič J., 1993b: Socialnogeografska transformacija in narodna identiteta : primer Slovencev na Koroškem. Geographica Slovenica 24, str. 65-72.

- Zupančič J., 1993c: The ethnic identity of Hungarians in the demographicaly threatened area of Prekmurje. Geografski zbornik 33, str. 131-139. 
- Zupančič J., 1994a: Ali je socialnoekonomsko in politično prestrukturiranje narodnih manjšin pogoj njihovega preživetja - primer manjšin v Sloveniji in Slovencev v sosednjih državah. V: P.Vencelj, V.Klemenčič in S.Novak Lukanovič (ur.), Manjšine v prostoru Alpe-Jadran, Ljubljana, str. 90-95.

- Zupančič J., 1994b: Les Slovenes en Autriche. Espaces, Populations, Societes 3, Lille, str. 323-329.

- Zupančič J., 1995: Some development problems of the Hungarian minority in Northeastern Prekmurje (Slovenia). V: K.Heffner in V.Klemenčič (ur.), Small Regions in United Europe - Macroregional and Social Policy, Opole, str. 44-53.

- Zupančič J., Repolusk P., 1995: Regionalism in Istria. V: M.Koter (ur.), Region and Regionalism - Social and Political Aspects, Opole-Lodz, str. 109-116.

\section{SPATIAL ASPECTS OF THE MINORITY PROBLEMS IN THE LIGHT OF SLOVENIAN SOCIOGEOGRAPHICAL AND POLITICOGEOGRAPHICAL INVESTIGATIONS}

\section{Summary}

The paper discusses the development and various aspects of sociogeographical and politicogeographical investigations of minority problems in Slovenia. On the motion made by Vladimir Klemenčič, Slovenian geographers began to investigate these problems by means of the sociogeographical concepts. Thus, they have efficiently followed the transformation of Slovenian space and society within the frame of the following processes: industrialization, urbanization, and abandoning agrarian activities accompanied with depopulation. With analysing the structural and functional aspects of minorities in the process of modernization, and forming the models of ethnic and regional development of the ethnically mixed border areas, the questions were also studied in detail and published in numerous publications, about the inclusion of these communities into the transborder flows, the maintenance of their identity in the changed social and spatial conditions, as well as the fostering of multilingual practice and interethnical relations. So by the intensity of the performed investigations in the field of minority problems as by their quality, Slovenian social and political geographies were completely included into the international streams and contributed an original research methodology to this field, for investigating the functions of local communities and minorities in the border areas, as well as the cultural aspects of transborder connectedness. However, numerous fields have been only partly investigated, such as the ethnicity and the identity of allochtonous minorities and other local and regional communities, as well as the questions of spatial organization and social groups, which are, in fact, the questions of maintaining 
the original territorial and cultural identity in the conditions of ever greater social, spatial and structural international integration representing a new challenge and new perspectives for social and political geographies in Slovenia and in the world. 